\title{
Hendelsesanalyser etter suicid - en vitenskapsteoretisk refleksjon
}

\author{
Av Arne Thorvik
}

ETTER ET SELVMORD vil omverdenen erfaringsmessig sitte igien med spørsmål. Hvordan kunne dette skje? Hva var dynamikken bak? Hva mer kunne man ha giort for å avverge? Hvis avdøde var i kontakt med psykisk helsevern, tenker de etterlatte ikke sjelden at helsevesenet burde ha giort mer for å forhindre at dette ble utfallet.

I Norge har flere helseforetak tatt i bruk det som kalles hendelsesanalyser etter en pasients suicid. Hendelsesanalyser ble introdusert av Helsedirektoratet for få år siden, som del av et generelt fokus på pasientsikkerhet, fortrinnsvis innen somatikk (Helsedirektoratet, 2016). Det siteres fra innledningen til håndboken:

«Helsetjenesten må forsøke å lære av de uønskede hendelsene for å forsøke å hindre at det samme skjer igjen. For å forstå årsakene til de uønskede hendelsene må hendelsene analyseres. Noen ganger kan det være enkelt. Andre ganger er det vanskelig å finne alle bakenforliggende årsaker uten å giøre en grundig analyse. Det er viktig å huske at selv om en hendelsesanalyse ser bakover giøres den for å forebygge nye hendelser i fremtiden».

Flere sykehus har opprettet egne team som forestår hendelsesanalyse etter en pasients suicid, forst ved å studere dokumentasion, deretter ved å interviue involvert personale.

\section{Materiale og metode}

Denne artikkelen er å forstå som en vitenskapsteoretisk refleksion rundt tiltaket som kalles hendelsesanalyser, vel å merke som anvendt innen suicidologi. Hvilket rasionale er ment å ligge til grunn, og i hvilken grad kan dette begrunnes?

Metodologisk bygger artikkelen på medisinsk og vitenskapsteoretisk litteratur som er kjent for forfatteren. Da artikkelen er å forstå som en prinsipiell drøfting, er det ikke giort strukturelt datasøk.

Av vitenskapsteoretiske tradisjoner er modellen utformet av Carl G. Hempel (1905-1997) vektlagt. Kortfattet kan denne og senere kritikk presenteres slik:

Vitenskapsteoretikere synes å samstemme i at vitenskap søker å se sammenhenger og grunnleggende strukturer («regularities»), utover analyse av enkelthendelser. Hempels såkalte deduktiv-nomologiske («cowering-law») modell tilsier at en vitenskapelig forklaring av et fenomen ikke bare kan baseres på partikulære fakta, men også at forklaringen bør inkludere en lovmessighet. Et kjent eksempel er at en bilradiator 


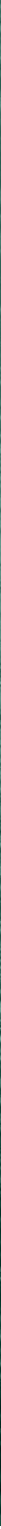

fylt med springvann vil sprekke dersom temperaturen faller under null grader: Vann utvider seg når det fryser (Hempel, 1942).

Mens Hempels modell har vist seg anvendbar innen naturvitenskapene, er det langt mer diskutabelt hvorvidt den kan legges til grunn innen humanvitenskaper. Særlig har vitenskapsteoretikere vært kritiske til at man innen humanvitenskap og psykologi, som ofte tar for seg komplekse årsakssammenhenger, kan formulere generelle lovmessigheter. I høyden vil man kunne postulere sannsynligheter eller risiko for at en enkelthendelse kan inntreffe (Lübcke, 1982).

Det er også relevant å vise til distinksionen introdusert av den tyske filosofen Wilhelm Dilthey (1833-1911) mellom forklaring og forståelse. Naturen kan objektiveres og forklares, mens psykisk fungering må forstås på bakgrunn av subjektive erfaringer giort oss tilgiengelige i en livssammenheng, og som inngår i en større kontekst. Humanvitenskaper har på denne måten et annet metodologisk grunnlag (Lübcke, 1982, s. 30).

\section{Helsedirektoratets tre spørsmål}

Ifølge Helsedirektoratets veileder forsøker en hendelsesanalyse å besvare følgende spørsmål: Hva har skjedd? Hvorfor har det skjedd? Hvordan forhindre gientakelse? (Helsedirektoratet, 2016, s. 43).

\section{Hva har skjedd?}

Innen suicidologi lar dette spørsmålet seg oftest besvare. En person er død ved selvmord. Likevel kan det enkelte ganger reises tvil om hendelsen faktisk er å klassifisere som selvmord. Sosiologen Durkheim definerte suicid som en intendert handling, som avdøde visste ville føre til døden. Senere kommentatorer til Durkheims verk har vist til det prinsipielt problematiske ved å avdekke avdøde menneskers intensjoner og viten (Douglas, 1968). Eksempelvis kan det i noen tilfeller være vanskelig å avgiøre om død ved skytevåpen eller i trafikk er ulykke eller suicid. Drukningsdød kan være selvmord, men også uttrykk for somatisk sykdom eller svekkelse, at avdøde overvurderte egne svømmeferdigheter, ulykke eller drap.

Det er også relevant å nevne at intervjuer med mennesker som har giort selvmordsforsøk har vist at de i mange tilfelle lar tilfeldigheter eller «skjebnen» råde med hensyn til om forsøket lykkes, og at intensionen om å dø på denne måten er ledsaget av en ambivalens (Hale, 1991). 
Medisinsk sett kan utfallet av et selvmordsforsøk (så som en selvpåført intoksikasjon) være tilfeldig.

\section{Hvorfor har det skjedd?}

I Helsedirektoratets veileder gis eksempler fra somatisk medisin som har et visst teknisk preg, som at medikasjon har vært fort feil i kurve.

Innen suicidologi er spørsmålsstillingen langt mer kompleks. I faglitteratur beskrives suicid som et multifaktorielt fenomen, som har ulik etiologi på individnivå (O'Carroll, 1993).

\section{Det foreligger empiriske studier som viser at selvmordstruede tenderer mot å vektlegge grunnene eller motivene for egen selvmordsatferd, mens behandler- personale ofte baserer sin forståelse av samme atferd på årsaksforklaringer.}

Som nevnt i en foregående artikkel, har engelsk filosofi tradisionelt gjort en distinksion mellom motiver («motives») og årsaker («causes») (Ryle, 1949/199o; Thorvik, 2018). Motiver (som likner det som kalles grunner («reasons»)) kan forstås som noe som «trekker» mot en handling, mens årsaker i større grad «skyver». I sin forståelse av suicid har psykodynamisk litteratur pekt på motiver (med ulik grad av bevissthetsnivå), så som ønske om gienforening med avdøde eller en type guddom, eller aggresjon mot seg selv eller gienlevende (Hale, 1991). Klinisk psykiatri har i større grad tatt for seg årsaker, som hallusinose eller depresion. Det foreligger empiriske studier som viser at selvmordstruede tenderer mot å vektlegge grunnene eller motivene for egen selvmordsatferd, mens behandlerpersonale ofte baserer sin forståelse av samme atferd på årsaksforklaringer (Michel et al., 1994).

Det synes åpenbart at flere faktorer må foreligge for at suicid skal kunne skje. Depresjon kan ses på som en årsak. Imidlertid er depresion et utbredt fenomen, de fleste med tilstanden giør ikke suicidforsøk, og ikke alle som suiciderer er klinisk deprimerte (selv om en definisjonsmessig (tautologisk) problematikk vil oppstå dersom suicidalitet anses som et spesifikt kjennetegn for depresion). Hallusinose fører i alminnelighet heller ikke til suicid.

Når det gielder motiver, vil man for enkelte kunne peke på muligheten av at avdøde kan ha hatt ønske om å straffe seg selv eller omverden etter alvorlig krenkelse eller relasionsbrudd. Krenkelse eller relasjonsbrudd kan i så fall betegnes som en utløsende faktor. Men det er fortsatt slik at de fleste som opplever dette ikke suiciderer, og at suicidet derfor må ha vært betinget av flere (fra før tilstedeværende) faktorer, og ses i lys av avdødes psyke og verdigrunnlag.

Kuriøst kan det nevnes at Freud i sitt siste verk medga at man ikke hadde lyktes i å lose det han tidligere hadde omtalt som «suicidalitetens gåte» (Freud, 1940; Thorvik, 2008). Gjennom tidene er det likevel fremsatt en rekke teoretiske modeller for å forstå selvmord (Menninger, 1966; Baumeister, 1990). Man kan innvende at det neppe finnes noen generell forståelsesmodell. Et suicid må (i den grad det er metodisk mulig) analyseres på et individnivå.

Det er nevnt at humanvitenskaper i noen sammenhenger kan angi sannsynligheter eller risiko for at en hendelse vil inntreffe. Retrospekt vil hendelsesanalyser kunne peke på faktorer eller faser som er kjent på gruppenivå som risikofylte (utskrivning fra døgnavdeling, brudd i relasion). Dybdeinterviuer med personale intenderer å rekonstruere avdødes egen opplevelse, og sannsynliggiøre interaksjoner mellom individet og behandlingen som ble gitt.

På det meste kan man derfor ha ambisjon om å forstå noe av dynamikken bak et giennomført suicid. Ambisjon om nøyaktig å fastslå «årsakene» til at suicid skjedde, synes urealistisk.

\section{Hvordan forhindre?}

Giennomført suicid kan ha mekaniske aspekter. I sykehus skjer de fleste selvmord ved strangulering eller hengning. Hvis man avgrenser spørsmålsstillingen til hvordan forhindre at denne typen selvmordsmetode lar seg anvende, kan det være mulig å gi relevante svar. Vitenskapsteoretisk vil hypotetisk kontrafaktiske setninger kunne sannsynliggiøre en årsakssammenheng. «Dersom pasientrommet ikke hadde hatt opphengspunkter, ville suicid ved hengning ikke ha kunnet skje» fremstår som et meningsfullt utsagn. Også setningen «dersom pasienten hadde hatt kontinuerlig tilsyn av personale, ville suicidet ha vært forhindret» synes å gi mening (hvis tilsyn forstås som et situasjonsbetinget mekanisk-preventivt tiltak. Som del av en lengre behandlingsprosess kan tett oppfølging på sikt også ha negative konsekvenser, så som regresjon. Kontinuerlig tilsyn som rutine vil på gruppenivå kunne ha som konsekvens at mennesker med selvmordsproblematikk vegrer seg for å søke hielp).

Langt vanskeligere blir det å postulere at tiltak utover de skisserte mekaniske kunne ha forhindret suicid. Dette kan illustreres ved følgende eksempler:

\section{Eksempel A}

Hvis en pasient (A) med kjent depresion har suicidert, kan retrospekt (hendelses-)analyse indikere at mer intensiv biologisk antidepressiv behandling (medikamenter, ECT) kunne ha virket preventivt. Å hevde dette på generell basis blir imidlertid feil. Det er ikke slik at medikamenter eller ECT i behandlingen av personer med depresion med nødvendighet forhindrer suicid. 


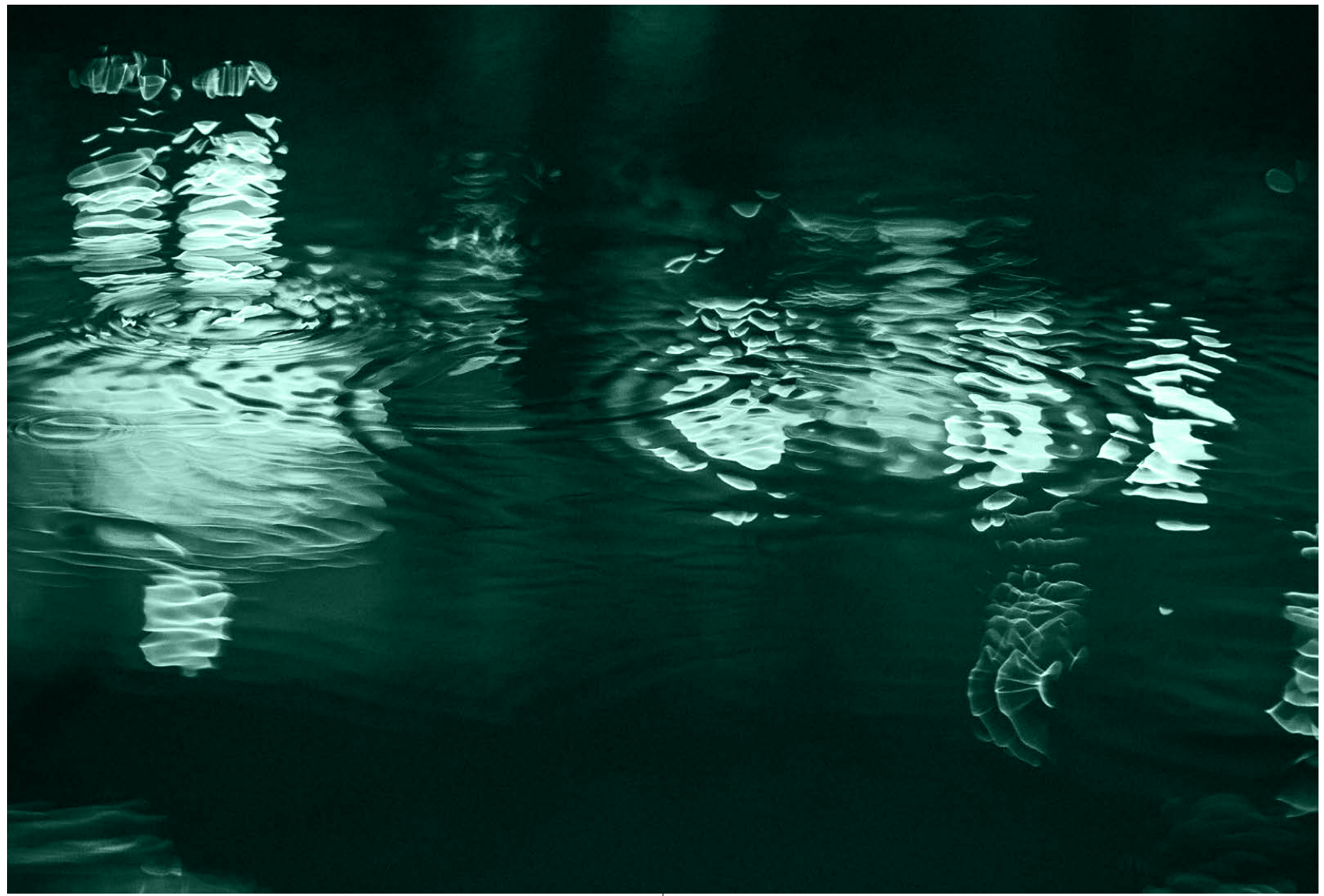

Vitenskapsteoretisk bør man vokte seg for tautologiske slutninger (gientakelse av samme argument), av typen «når antidepressiva er middelet som kan forhindre suicid, vil suicid kunne skje når antidepressiva ikke gis». Dersom analysen av As forhistorie tilsier at A tidligere responderte godt på biologisk antidepressiv behandling, men at dette var seponert da A døde, kan man med noen grad av sannsynlighet hevde at mer intensiv biologisk terapi kunne ha forhindret As suicid. Men også en slik forbeholden påstand er forbundet med stor usikkerhet. Depresjoner kan ha ulik etiologi på ulike tidspunkt, og selvmordstruede har selv beskrevet at dynamikken bak suicidalitet kan oppleves forskjellig fra gang til gang (Thorvik, 2011). Også Felleskatalogen anfører at bruk av antidepressiva kan være forbundet

\section{I noen situasjoner vil man kunne hevde at tvang heller kan oke suicidfare ved eksempelvis å fremme regresjon, eller aggresion mot behandlerapparat fremfor allianse.}

med øket suicidalatferd for noen pasientgrupper, og at risiko for selvmord kan øke i de første fasene av en bedringsprosess.

\section{Eksempel B}

Hvis en pasient (B) motsatte seg frivillig innleggelse, og så suiciderte, kan retrospekt (hendelses-)analyse indikere at tvangsinnleggelse kunne ha forhindret suicid hos B. Igien blir det feil å hevde dette på generell basis. Det er ikke slik at tvangsinnleggelse i sin alminnelighet hindrer at suicid giennomføres. Nok en gang bør man vokte seg for tautologiske slutninger, av typen «når tvangsinnleggelse er middelet som kan forhindre suicid, vil suicid kunne skje når pasienten ikke blir tvangsinnlagt». Kanskje kan man med basis i Bs forhistorie, med detalikunnskap om hvordan $\mathrm{B}$ reagerte på frivillige og tvungne tiltak, hevde en viss sannsynlighet for at tvungen innleggelse ville ha kunnet forhindre suicid hos B. Igien er det slik at dette utsagnet er forbundet med stor usikkerhet. Etiologi kan være ulik fra gang til gang, og et enkeltindivid kan reagere ulikt på et spesifikt tiltak på ulike tidspunkt. I noen situasjoner vil man kunne hevde at tvang heller kan øke suicidfare ved eksempelvis å fremme regresjon, eller aggresion mot behandlerapparat fremfor allianse. 


\section{Konklusjon}

Som nevnt i innledningen (og som flere har erfart) er selvmord en hendelse som setter i gang følelser og reaksjoner, da særlig hos nærstående og behandlerpersonale. Etter et suicid vil mange spørre «hvordan kunne dette skje», og «er det noe vi kunne ha giort for å forhindre».

Ikke minst av den grunn er en hendelsesanalyse å anse som et godt tiltak. Vitenskapelig sett må man imidlertid være innforstått med metodens begrensninger. En hendelsesanalyse av suicid er et forsøk på retrospektiv forståelse av et komplekst og individuelt fenomen, og konklusjoner om årsaksforhold bør formuleres med forsiktighet. Med unntak av noen betraktninger rundt suicidets faktiske eller «mekaniske» aspekter, kan man i høyden postulere enkelte sannsynligheter for hvilken dynamikk som var bakenforliggende og hvordan suicid kunne ha vært forhindret. Eventuelt vil man kunne hevde at kiente risikofaktorer burde ha vært mer vektlagt. Muligens vil den empiri som fremkommer av analyse av et eller flere enkelttilfelle kunne brukes til å utkrystallisere nye hypoteser om generelle sammenhenger, som kan bidra til en mer detaljert forståelse, og som i neste instans vil kunne brukes i selvmordsforebygging i fremtid.

Vitenskapsteoretisk er hendelsesanalyser å sammenlikne med en «hvordan mulig» («how possible») -forståelse, sett i retrospekt. Fenomener som forut for suicidet ble ansett som ubetydelige eller trivielle, kan nå komme i nytt lys. Eksempelvis kan det etter et suicid gis betydning at avdøde hadde formidlet noe kryptisk eller humoristisk om livets mening, eller (paradoksalt) at vedkommende på et tidspunkt virket lettere til sinns (som også er beskrevet som et mulig varselssignal, kanskje ved at vedkommende «har bestemt seg og funnet roen» (Hale, 1991)). Innen flere fagfelt er det beskrevet en tendens til det som kalles «hindsight bias»: Når utfallet er kjent, blir forutgående begivenheter tolket slik at nettopp dette utfallet fremstår nødvendig eller som en naturlig følge (Hawkins \& Hastle, 1990).

For et komplekst fenomen som suicid bør man imidlertid ikke ha ambision om å «årsaksforklare» eller beskrive det som vitenskapsteoretisk har vært kalt «why necessary». En slik ambisjon kan i så fall sammenliknes med hva en teoretiker innen feltet har omtalt som en «deterministisk myopi» (Dray, 1957, s. 168).

Livet forstås baklengs, men må leves forlengs, skriver Kierkegaard.

\section{REFERANSER}

Baumeister, R. (1990). Suicide as escape from self. Psychological Review, 1990, Vol. 97, No. 1, 90-113.

Douglas, I. (1968). Suicide - social aspects. I: Sills \& Merton (eds): International Encyclopedia of the Social Sciences. Vol. 15. New York: The Macmillan Company \& The Free Press: $375-385$.

Dray, W. (1957). Laws and explanation in history. Oxford University Press.

Freud, S. (1940). Abriß der Psychoanalyse. I: Gesammelte Werke, 17: 63-138. (Engelsk utgave (2003): An outline of psychoanalysis. Penguin Modern Classics).

Hale, R. (1991). Suicidal acts. I: Teremy Holmes (red): Textbook of psychotherapy in psychiatric practice. Edinburgh: Churchill Livingstone.

Hawkins, S. \& Hastle, R. (1990). Hindsight: Biased judgements of past events after the outcomes are known. Psychological Bulletin 107 (3): 311-327.

Helsedirektoratet (2016). Risikoanalyse. Hendelsesanalyse: Håndbok for helsetienesten (IS-5038).

Hempel, C.G. (1942): The Function of General Laws in History. The Tournal of Philosophy, Vol 39 (2): 35-48.

Lübcke, P. (1982). Vor tids filosofi - vitenskap og sprog. Kobenhavn: Politikens forlag.

Menninger, K. (1966). Man against himself. New York: Harvest/Harcourt Brace Tovanovich.

Michel K., Valach L. \& Waeber V. (1994). Understanding deliberate selfharm: The patients' views. Crisis 15 (4): 172-178.

O'Carroll, P. (1993). Suicide causation: pies, paths, and pointless polemics. Suicide and Life-Threatening Behavior, Vol. 23(1): 27-36.

Ryle, G. (1949/1990). The Concept of Mind. Penguin Books.

Thorvik, A. (2008). Å stå på Freuds skuldre - hovedlinjer i psykodynamisk forståelse av suicide. Suicidologi 13 (3): 5-9.

Thorvik, A. (2011). Suicid som etisk fenomen - teoretiske og empiriske perspektiver. Oslo: Unipub.

Thorvik, A. (2018). Strukturerte selvmordsrisikovurderinger - en vitenskapsteoretisk analyse. Suicidologi 23 (2): 22-28.

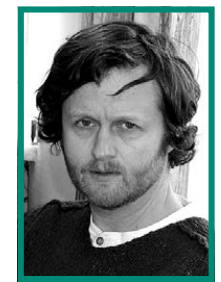

ARNE THORVIK er psykiater og avd.overlege ved Psykiatrisk fylkesavdeling ved Sykehuset $\mathrm{i}$ Vestfold. Han disputerte for sin doktorgrad i 2011 med en avhandling bl.a. basert på dybdeintervjuer av pasienter med suicidproblematikk. Thorvik er medlem av redaksjonskomiteen ved Suicidologi. 